\title{
Functional relevance of students'
} study

Tobias Kärner ${ }^{*}$ and Julia Warwas

*Correspondence:

tobias.kaerner@uni-bamberg.de Lehrstuhl für

Wirtschaftspädagogik

(Chair of Business Education and Educational Management)

Otto-Friedrich-Universität

Bamberg, Kärntenstraße 7,

96052 Bamberg, Germany

\section{Springer}

\begin{abstract}
Background: Descriptive accounts of instruction in German vocational schools consistently indicate whole-class dialogue to be prevalent. We aim to extend previous research by elucidating pedagogically valuable dialogic practices that facilitate conceptual understanding, and by empirically investigating factors that promote or hinder student engagement in these practices. We focus on prior knowledge in the domain discussed, because knowledge differences count among the prime sources of heterogeneity among vocational students in Germany. However, with survey studies suggesting a decisive role of communication apprehension, we also intend to explore if feelings of uncertainty in ongoing verbal interactions moderate the knowledgeengagement relationship, while controlling for potential confounding and competing influences.
\end{abstract}

Methods: The study employs a longitudinal, multi-method design. It combines video recordings of nine consecutive lessons about Economic Business Processes in two classes, preceding tests on intellectual abilities and economic literacy, questionnaire reports of teacher-student relations and instructional clarity, and Continuous State Sampling during instructional activities. Interactional features were classified by applying a fine-grained category system that distinguishes coordinating gestures as well as types and qualities of dialogic exchanges.

Results and discussion: Hierarchical regression analyses provide some evidence that getting opportunities to engage in valuable components of classroom dialogue depend on domain-specific prior knowledge. Differential teacher treatment exists in cold calling strategies and demanding follow-up techniques, even after controlling for students' gender. Moderated regressions for effects of prior knowledge and situational uncertainty on students' communicative behaviours indicate that advanced knowledge structures do not affect the mere quantity of a student's verbal contributions. But they robustly predict the degree of elaboration in given answers, together with positive teacher-student-relations, and net of the influences of student gender and instructional clarity. Feelings of uncertainty neither keep students from participating in classroom dialogue nor impair the quality of their contributions. 
Conclusions: Results suggest that domain-specific prior knowledge is not an indispensable prerequisite to contribute 'somehow' to classroom dialogue. However, it is a decisive factor for participation and involvement in those dialogic practices that promote cognitive elaboration. Thus, when researching Matthew effects, differences concerning student engagement in pedagogically valuable features of classroom dialogue might aid in identifying how instructional communication enhances or reduces differences in learning gains.

Keywords: Classroom dialogue, Vocational schools, Domain-specific prior knowledge, Situational uncertainty

\section{Background}

Despite persistent calls for action-oriented learning, classroom dialogue takes up the major portion of instructional time in commercial vocational schools in Germany (Götzl et al. 2013; Seifried et al. 2006). However, investigations into how dialogic exchanges relate to learning gains suggest that not all kinds of verbal interactions are equally conducive to the students' conceptual development and understanding (Wuttke 2012; for other educational settings, see Gayle et al. 2006; Murphy et al. 2009). Consistent with constructivist perspectives on teaching and learning, empirical evidence indicates that effective communication practices are those that trigger and perpetuate deep cognitive elaboration of the learning material, thus allowing students to progressively build, rearrange, refine and revise their conceptions of the topics concerned (e.g., Baumert et al. 2010; Loyens and Gijbels 2008; Slavin 2011).

Research regarding critical factors that facilitate or impede effective communication practices yields more ambiguous results (c.f., Howe and Abedin 2013). Among the multitude of potentially enabling and restricting conditions, students' feelings of confidence are considered to play a crucial role and appear in numerous self-report questionnaires (c.f., Rocca 2010). By contrast, students' aptitudes such as domain-specific prior knowledge are widely neglected, even though they figure prominently in explanatory models of academic achievement (e.g., Hailikari et al. 2008). In Germany, prior knowledge differences among students in vocational classes are usually high, owing to their varied educational careers and heterogeneous workplace experiences (Seeber 2009).

Against this background, we chose vocational classrooms as the setting in which to examine effects of domain-specific prior knowledge on students' engagement in classroom dialogue. By using individual ability-achievement discrepancy (AAD) as the main predictor, we rely on a distilled measure of prior knowledge, which is adjusted for intellectual abilities (Ziegler et al. 2012). We expect that individual AAD affects the extent to which students get and seize opportunities to engage in pedagogically valuable components of classroom dialogue. More precisely, we assume that individual AAD predicts not only how students take an active part in verbal interactions, but also how teachers allocate tasks and speaking turns among them. In a supplementary and more exploratory step, we investigate if students' prevailing feelings of uncertainty during the interaction process, i.e. the extent of perceived situational uncertainty, moderate effects of AAD on either the quality of contributions or signalled willingness to contribute. By controlling for selected student and teacher characteristics that are discussed in the literature on 
instructional communication we also attend to knowledge-independent influences that might rival the effects of interest.

To substantiate our assumptions, we first set out pedagogically valuable features of classroom dialogue by summarising existing findings on effective verbal teacher-student interactions. Then we present arguments and evidence on how inter-individual differences in prior knowledge can impact both students' and teachers' communicative behaviours. Furthermore, we characterise the potentially inhibiting role of perceived uncertainty in ongoing interactions and elucidate further sources of systematic variation in observable communicative practices. Finally, we highlight blind spots and inconsistencies in previous research in order to specify the questions and hypotheses guiding the present study.

Subsequent statistical analyses employ data from a mixed-methods study that we conducted in two German vocational classrooms during nine lessons on Economic Business Processes. In-situ data collection included video recordings of all verbal interactions, which were coded afterwards according to type and quality, as well as Continuous State Sampling on the part of the students, who reported (among other things) on levels of perceived uncertainty in 10-min intervals. Eight weeks before the lessons took place, two standardised tests were administered to the students to assess general cognitive capabilities and domain-specific prior knowledge. At the same time, students rated teacherstudent-relations and the teacher's instructional clarity by filling in a questionnaire. Data were subjected to hierarchical and moderated regression analyses.

After discussing results, strengths, and limitations of the study, we conclude with practical implications and suggestions for further research.

\section{Structure and quality of classroom dialogue}

Classroom dialogue typically evolves through rapid successions of teacher Initiation, student Response, and teacher Follow-up (IRF structure; c.f., Howe and Abedin 2013; Lyle 2008; Sinclair and Brazil 1982). But given that verbal exchanges can also be fuelled by the learners' own questions, we consider (a) both teacher and student questions, (b) student answers to the teacher or to classmates, and (c) a range of teacher follow-up moves. In addition, we demarcate different qualities of these components in order to characterise pedagogically valuable features of verbal interactions.

\section{Teacher questioning and student-generated questions: demanding recall or deep reasoning?}

Questions can differ tremendously with respect to the cognitive challenge they pose to the respondent (Renaud and Murray 2007). If they merely require recognition and recall or aim to elicit answers that can easily be categorised as right or wrong they are usually referred to as lower-order or constrained questions. By contrast, higher-order or deep-reasoning questions invite the recipient to draw inferences, transfer ideas to specific contexts, tie together information from multiple sources, or judge the appropriateness of means. Requests for causal antecedents and consequences (Why? What happens if?), for goals (What is the purpose of?), and for procedural or instrumental enablement (How?) particularly relate to these higher levels of analysis, application, synthesis, and evaluation (Graesser and Person 1994). By now, a substantial body of research indicates 
that higher-order questions-posed either by the teacher or the learners themselvesare associated with students' learning gains, such as improved reading comprehension, critical thinking, or application of course content in subsequent tests (e.g., Chin and Osborne 2008; Gayle et al. 2006; Özerk 2001; Seifried and Sembill 2005; Taboada and Guthrie 2006).

\section{Student answers: simple or elaborated?}

However, conceptual understanding does not automatically follow from the act of posing a demanding question, but rather originates from a cascade of mental operations in search for a satisfying answer (Chin and Brown 2000). Verbalisation can promote this process if it compels students to explore the composition and relations of familiar and new elements within a subject area, to straighten out their lines of thought, and to express them in ways that are comprehensible to listeners (e.g., Reznitskaya et al. 2001; Wuttke 2012).

Providing thorough explanations as well as exchanging justified arguments count among those strategies that demonstrably contribute to improved critical reasoning and problem solving (Berland and Reiser 2009; Nussbaum 2008). Whereas mentioning catchwords or making bare claims primarily stabilises existing conceptions, conceptual differentiation and enrichment can occur when students explain their attempts to solve a problem while carefully examining initial conditions, identifying goals and obstacles, specifying rules and their respective scope of application, and weighing the pros and cons of alternative procedures (e.g., de Leeuw and Chi 2003; Hmelo-Silver 2004; van Blankenstein et al. 2011; Webb et al. 2014).

\section{Teacher follow-up techniques: evaluating, supporting, or prompting?}

The last step of the IRF structure spans a wide range of verbal signals that are more or less compatible with genuinely dialogic modes of instructional communication and also more or less suited to sustain learners' cognitive activation (e.g., Wells and Arauz 2006). We propose a three-stage taxonomy of follow-up moves:

1. Short evaluative remarks represent a pragmatic and popular approach to react to students' contributions (e.g., Airasian 1997; Cullen 2002). Satisfying answers are confirmed or even reinforced by way of repetition in order to emphasise important statements (e.g., "That's right! It's $10 €$ of discount deducted."). Flawed answers are clearly rejected, and the initial question might simply be passed on (e.g., "No. Who has another result?"). Although instant feedback on task accomplishment or failure can be conducive to learning when task complexity is low (Kluger and de Nisi 1996), monotonic evaluative remarks run the risk of fostering trial-and-error tactics rather than joint constructions of meaning, because learners attune themselves to do guesswork on what the teacher wants to hear (Chin 2006; Hattie and Timperly 2007; Smith and Higgins 2006).

2. Other reactions aim at teacher repair or enrichment of student answers. This approach often consists of reformulations, by which a teacher exposes and resolves an error by paraphrasing a student's utterance in whole or in part (Lyster and Mori 2006; Lyster and Saito 2010). Thus, reformulations can provide linguistic scaffolds 
for the appropriate use of terms and assist in encoding new representations (Leeman 2003). But the repair-and-enrichment approach can also adopt the shape of affirmation/correction cum direct instruction (Chin 2006). Here, the teacher briefly confirms or rectifies an answer (or at least calls for heightened attention) and immediately proceeds to expository talk in order to clarify or complement a student's proposal, or to elucidate solution paths and pitfalls in greater detail. Apart from supporting and safeguarding students' thinking on their way from current to desired understanding, teacher repair or enrichment serves as a reliable means to steer discussions towards certain ends (see also Ding et al. 2007). Yet, whereas reformulations can be woven into verbal exchanges in a rather unobtrusive manner, communication can easily relapse into a transmissive and authoritative mode when teachers take over a dominant part (Chin 2006). Moreover, a supportive 'overdose' can restrict insightful processes and discoveries on the part of the learners (Walshaw and Anthony 2008).

3. When prompting or responsive questioning techniques are applied, the teacher playfully pushes students to self-repair or extends and probes their own lines of thought (Lyster and Saito 2010; Smith and Higgins 2006; Walshaw and Anthony 2008). Prompts may be delivered, for instance, as a simple clarification request (e.g., "Sorry, I didn't get your point.") or as repetition with rising intonation to indicate irritation or doubt (e.g., "XY increases our firm's profit? Really?”) (Lyster and Mori 2006). Responsive questioning can take place through zooming, in which a teacher poses a supplementary question that focuses on general concepts or fine distinctions (e.g., "Hmmm, yes. And which essential principal of accounting can you discover in the current example?"). It also includes constructive challenge (Chin 2006), which confronts the student with counterarguments, counterexamples, changing scenarios, and the like (e.g., "Okay. Would you stay with this decision if the purchase price rises $3 \%$ ?). The benefits of these techniques are particularly evident in studies on cognitive engagement in mathematical problems. Here, the teacher's sustained demands for meaningful explanations stimulate sophisticated and targeted mathematical reasoning, whereas a shift of focus to deliver correct answers favours a decline to the level of unsystematic exploration (Hennigsen and Stein 1997).

\section{The (in)significance of prior knowledge for verbal interactions}

Even though it seems desirable that all students engage in verbal interactions that allow them to elaborate thoroughly on learning contents, several studies imply that chances to take part and to get involved in such 'high quality' interactions depend on a student's membership in particular ability groups.

\section{Prior knowledge as a determinant of the amount and quality of students' participation}

One phenomenon that has been repeatedly confirmed is the consolidation of responsibility (Howard and Baird 2000; Karp and Yoels 1976). It denotes an implicit norm according to which "in the typical classroom, participation will be consolidated in the hands of the few, with the majority of students being passive observers or only occasional participants" (Howard and Baird 2000, p. 701). Besides ethnicity and gender, attainment belongs to the most reliable predictors of a student's share of contributions. Although 'high attainers' have been characterised in different ways, such as in terms of general 
cognitive capabilities, prior knowledge, or past academic achievement, they have been found to contribute more often and on higher levels of conceptual complexity both in response to teacher stimuli and during small group discussions (Howe and Abedin 2013; von Aufschnaiter et al. 2008; Wuttke 2005).

In particular, domain-specific prior knowledge is deemed to be a decisive factor in that it implies a well-organised structure of domain-specific concepts in the learner's mind (Barry and Lazarte 1998; Kintsch 2005). Students who have already developed rich and differentiated mental models should, for instance, be able to generate higher order questions (Miyake and Norman 1979; Taboada and Guthrie 2006). Indeed, several findings suggest that learners who are not familiar with a particular topic primarily pose basic orienting questions in their attempt to mend declarative knowledge deficits, whereas learners with high prior knowledge probe into causal and instrumental relations more often (e.g., Chin and Osborne 2008; Costa et al. 2000; Scardamalia and Bereiter 1992).

\section{Differential teacher behaviour towards high- and low-achievers as a regulator of students' involvement}

Research on differential teacher treatment suggests that teachers create comparably poorer learning conditions and fewer opportunities to demonstrate mastery for students with low academic achievement than for high-achieving classmates. They do so, for instance, by granting less time to answer questions, giving more negative feedback, paying less attention to proposals, providing less assistance in failure situations, or even rewarding inappropriate behaviour (Bohlmann and Weinstein 2013; Eccles and Roeser 2012).

Preferential behaviour towards high achievers during whole-class dialogue might owe to the teachers' pragmatic goals to tightly control the course of conversations and make headway in the curriculum. Accordingly, observations in German and Swiss schools demonstrated that in some classes, students' chances to be called on by the teacher were indeed influenced by their factual levels of prior knowledge, which had been tested in advance (Lipowsky et al. 2007). Yet most explanations refer to a more subtle mechanism and posit that teachers' perceptions or expectations about differing abilities of students foster differential interaction patterns (Bohlmann and Weinstein 2013; Rubie-Davies 2007). Even in vocational classroom settings, early investigations showed that teachers' subjective judgements of student characteristics significantly predict task assignments and support, thereby producing or increasing ability-related differences among their students (Sembill 1984, 1987). These findings provoke further questions on the degree of concurrence between expected and factual achievement and thus, on teachers' diagnostic competences. A recent meta-analysis (Südkamp et al. 2012) reports an overall positive and substantial mean correlation of 0.63 , suggesting that the accuracy of teachers' ability-related judgements is remarkable but "far from perfect" (p. 755), and varies depending on test characteristics and available sources of information. Rost and Hanses (1997) find that teachers rely heavily on school grades when forming ability-related judgements, and therefore often fail to identify highly gifted (i.e. highly intelligent) underachievers. Consequently, not only teachers' expectations of prospective academic achievement, but also their impressions of basic intellectual abilities seem at least to intermingle with past academic performance (such as prior knowledge documented in a test). Altogether these 
findings point to the importance of conceptual clarity when analysing potential influences on teachers' communicative practices.

\section{Situational uncertainty as an inhibiting factor of voluntary participation}

Numerous surveys among students have identified confidence to be a major predictor of verbal engagement, and uncertainty to foster avoidance and withdrawal (c.f., Rocca 2010). Therefore, feeling confident about verbalising one's thoughts is considered an indispensable prerequisite for students' willingness to take part in classroom dialogue. As Bourhis et al. (2006) set out, classroom dialogue can be an anxiety-producing event, because contributions are subject to evaluation at both an academic and social level. Many students choose to remain silent because they are concerned about failing or being stigmatised by classmates (e.g., Byrne et al. 2012; Seifried and Sembill 2005; Weaver and Qi 2005).

However, questionnaires usually tap global assessments of feelings and behavioural consequences in past or imagined communication episodes. Stated differently, most studies focus on trait-like or generalised-context forms of communication apprehension-the former being an enduring, global disposition of a person, the latter generalised fears with regard to certain communication settings (Gardner et al. 2005; McCroskey 2012). Furthermore, they face problems of common method variance, which can produce artificially inflated correlations (e.g., Howard and Baird 2000). The functional role of situational uncertainty, i.e. the role of immediate aversive states, has, to the best of our knowledge, not yet been explored using in situ measurements. As opposed to stable fears of expressing one's ideas in whole-class dialogue in general and in principle, situational uncertainty might fluctuate considerably in ongoing communication processes, depending not only on topical familiarity but also on perceived social climate in the current group or classroom setting (MacIntyre 2007).

\section{Other teacher- and student-dependent causes of systematic variation in dialogic engagement}

Although we find strong arguments for the impact of knowledge and uncertainty in dialogic engagement, it would be risky to neglect potentially confounding or competing sources of variation. We therefore address (perceived) teacher-student relations, instructional clarity, and student gender.

First of all, there is a broad scholarly consensus that a classroom climate based on trust, fairness, emotional warmth, respect and assistance is particularly suited to foster student's voluntary participation by way of decreasing implicit power differentials and increasing students' comfort and confidence (e.g. Fassinger 2000; Hyde and Ruth 2002; Rocca 2010; Weaver and Qi 2005). Moreover, the teacher is deemed to play a crucial role in creating this caring and supportive learning environment (Reyes et al. 2012). Correspondingly, students report to refrain from sharing their ideas if they feel that the teacher ignores or ridicules them or behaves in a spiteful, offensive or overcritical manner (e.g., Rocca 2009; Wade 1994). In contrast, they report to contribute to discussions if they experience their teacher to be encouraging, approachable, attentive, empathetic, integrating and appreciative (Fassinger 1996, 2000; Mottet et al. 2004; Phoenix 1987). 
Another aspect of the broader learning environment pertains to teacher's instructional clarity (e.g., Metcalf 1992). Interestingly, research on this dimension has not only demonstrated strong relations between instructional clarity and subsequent learning outcomes but also a remarkable conformity between student and observer ratings on different dimensions of clarity (Hines et al. 1985). A look at some salient dimensions reveals that perceived instructional clarity (or vagueness) might provide facilitation (or an obstacle) for students to engage in classroom dialogue that cannot easily be offset by prior knowledge in the domain discussed (e.g., Chesebro 2003; Simonds 1997). In a narrow sense, clarity describes verbal skills such as using a precise and plain language or offering various examples and illustrations. In a wider sense, clarity also means to give orientation by informing about the goals of a lesson, to 'stay on track' regarding the topics, to proceed in comprehensible steps, or to grant time to think, practice and repeat.

As mentioned earlier, several studies suggest that student gender affects the extent to which students participate in classroom dialogue. But sex inequality is also discussed with regard to the degree and nature of involvement (see Jones et al. 2006 for theoretical underpinnings). Even though meta-analytic evidence indicates that teachers do initiate more interactions and, in particular, more negative interactions in terms of critique and reprimands with boys, these findings remain inconclusive, as effect sizes were heterogeneous and could not be explained by available moderators, namely teacher gender and school type (ibid.). Howe and Abedin (2013) conclude from their qualitative literature review that the proportional bias towards male contribution owes to both teacher-selection when it comes to choosing among students with their hand raised, and self-selection, as boys respond to teacher stimuli more often by calling out without being invited. But these authors also stress that inconsistent findings result from neglecting the combined effects of different student characteristics. They propose 'high attaining boys' to be the group that often dominates dialogic exchanges.

Indeed, recent findings on verbal interactions in physics classrooms located in Swiss and German high schools underscore the benefits of analysing student gender in conjunction with ability-related and motivational characteristics while carefully attending to different kinds of contributions (Jurik et al. 2013). The authors demonstrate that although boys in general engaged in classroom dialogue more often, with longer speaking times, and in more elaborated ways, 'student profiles' at least partly compensated for this imbalance. Girls with a 'strong' profile (consisting of high general cognitive abilities, advanced knowledge in physics, as well as a marked interest and positive academic self-concept in physics) differed considerably from other girls in terms of the frequency and duration of utterances and, in particular, the mere amount of answers given. On the other hand, only additive effects were evident in the quality of students' contributions. Boys in general as well as 'strong' learners in general were found to act as 'equal conversation partners' of the teacher more often, introducing ideas and arguments that the teacher picked up, developed further and integrated into ongoing discussions.

\section{Aims and hypotheses}

The present study investigates the influence of students' domain-specific prior knowledge and prevailing feelings of situational uncertainty on verbal interactions during 
whole-class dialogue in vocational education. Three main questions arise from our literature review that address the ways in which students get and seize opportunities to engage in pedagogically valuable elements of this dialogic exchange, i.e. elements that are particularly suited to promote conceptual understanding and development:

1. How do teachers allocate speaking turns and tasks among students with different levels of domain-specific prior knowledge?

2. How does prior knowledge affect the frequency and quality of students' contributions to classroom dialogue?

3. How do students' prevailing feelings of uncertainty during verbal interactions impact the quality of their contributions or their signalled willingness to contribute?

Besides a dearth of studies attending to these issues in the context of vocational classrooms, our literature review revealed two further striking features of extant research. The first concerns a multitude of terms pertaining to the central explanatory variable, which are sometimes used synonymously (e.g., prior knowledge, attainment, cognitive characteristics, cognitive abilities, and past academic achievement). Therefore, we opted for a distilled measure of domain-specific prior knowledge, which is adjusted for general intelligence. By using AAD as the predictor variable, we prevent statistical effects of prior knowledge from being confounded with the learners' general cognitive capabilities to follow the course of conversations, such as perceptivity, powers of concentration, or logical thinking. It should be noted, however, that this objective measure does not necessarily accord with teachers' subjective judgements.

The second feature is a predominance of questionnaire approaches to studying students' self-perceptions in past or fictitious interactions, which are rather remote from their lived experiences in actual, ongoing communication episodes. By analysing situational uncertainty instead of dispositional or context-bound forms of communication apprehension, the focus shifts from persistent tendencies to refrain from participation to factors that are more dependent on the perceived properties of the current interaction process. Thus, we rely on Continuous State Sampling for measuring emotional experiences that are encountered in the course of verbal interactions and may discourage students from contributing to classroom dialogue or hamper the quality of their contributions-even if they are well versed in the subject.

\section{Hypotheses concerning communicative behaviours of teachers}

Following research on differential teacher treatment, we expect teachers to interact more often with students who possess high prior knowledge in a given domain than with their less knowledgeable classmates. We also expect them to interact with highly knowledgeable students more often on levels that are cognitively demanding, particularly by posing questions that require analysis, application, synthesis, and evaluation, and by following up on students' answers with utterances that push them to self-repair or probe and extend their lines of thought. We therefore assume that domain-specific prior knowledge (measured as individual AAD) predicts ...

H1a: ... the frequency in which a student is called on by the teacher.

H1b: ... the quality of teacher-to-student interactions in terms of deep-reasoning questions. 
H1c: ... the quality of teacher-to-student interactions in terms of prompts and responsive questioning.

\section{Hypotheses concerning communicative behaviours of students}

Conforming to studies on students' participation and the consolidation of responsibility, we assume that highly knowledgeable students are generally more 'talkative' than others. We further propose a conceptual-level correspondence between students' mental models of a given domain and the quality of their verbal contributions. Consequently, we assume that domain-specific prior knowledge (measured as individual AAD) predicts ...

H2a: ... the frequency in which a student signals his/her willingness to contribute by way of raising a hand or calling out.

H2b: ... the amount of a student's deep-reasoning questions.

H2c: ... the amount of a student's elaborate answers.

Contrary to previous studies that have analysed behavioural consequences of the learners' global or retrospective self-assessments, we aim to explore if, in ongoing communication episodes, prevailing feelings of uncertainty impede active participation or impair the quality of students' contributions in spite of a solid knowledge base. Theoretical considerations suggest that perceived situational uncertainty might moderate the effects of domain-specific prior knowledge ...

H3a: ... on a students' signalled willingness to contribute (raising a hand/calling out).

H3b: ... on the amount of a student's deep-reasoning questions.

H3c: ... on the amount of a student's elaborate answers.

\section{Consideration of potential confounders}

All statistical models include student gender as a control variable, because research on sex inequalities in instructional communication suggests that gender might add to effects of prior knowledge on both student's involvement and participation. When examining the ways in which students seize opportunities to contribute to classroom dialogue, we also adjust for perceived teacher-student relations, which might alleviate feelings of uncertainty, and perceived instructional clarity, which should facilitate students' engagement in general.

\section{Methods}

\section{Sample characteristics}

In a short-term longitudinal study covering 3 weeks, $9 \times 45$ min of instructional activities in two classes of a public vocational school for commercial and administrative occupations in Germany were videotaped (Kärner 2015). Both classes were attended by industrial clerks in training and dealt with topics in the curricular field of Economic Business Processes when observations took place. Therefore, communication centred around market-oriented business processes, particularly around tasks, regulations and instruments for the planning and controlling of production as well as of purchase and sales transactions. The level of difficulty inherent in the contents and tasks of the observed lessons was assessed by student ratings. Overall, perceived difficulty was rated below average and did not deviate significantly between the classes (c.f. Kärner 2015). Classes differed in the extent to which student-centred and teacher-directed learning 
activities were employed. However, for the purposes of the present investigation, coding procedures and statistical analyses were strictly confined to those instructional phases in which whole-class dialogue with its characteristic IRF-patterns occurred.

The teachers were male and both possessed high levels of professional experience. The student sample we used to examine our research questions comprises 49 of 53 students (17 male, 32 female) with a mean age of 19.2 years $(S D=3.55)$, who were all in their first year of apprenticeship. Three students were excluded because they were absent on the day when student characteristics were assessed. Another student biased statistical results because of extremely low scores in the tests that were applied, which may have resulted from insufficient German language skills.

\section{Research design}

Adopting a product-process approach for examining instructional activities in natural educational settings, we measured students' intellectual abilities and domain-specific prior knowledge as well as student ratings of global teacher characteristics 8 weeks before scrutinising classroom interactions (see Fig. 1).

Data collection during instructional processes took two forms. Firstly, Continuous State Sampling served to track students' own perceptions of ongoing interactions. This method offers a high degree of ecological validity and differs from other forms of Experience Sampling in deploying highly frequent and equidistant measurement points (Csíkszentmihályi and Larson 1987; Sembill et al. 2002, 2008). Students reported on experienced uncertainty in 10-min intervals via mobile handheld computers, allowing for a maximum of 38 measurement points per person. Due to minor missing data, on average 36 measurements per person are available in the described sub-sample, accumulating to a total of 1781 state reports stemming from 49 students. Additionally, video recordings of all nine lessons were made. Interactional features of whole-class dialogue were categorised according to their type and quality. In sum, we coded 841 utterances and 532 coordinating gestures that serve as detailed descriptors of the participants' communicative behaviour.

\section{Instruments and operationalisation of constructs}

Intellectual abilities were assessed using the "Culture Fair Test" (CFT 20-R) from Weiß and Weiß (2006), which taps general fluid ability. Students worked on 45 graphically presented multiple-choice tasks pertaining to logical series, classifications, and matrices. Achieved scores in all three areas were added up to produce a total CFT score for each

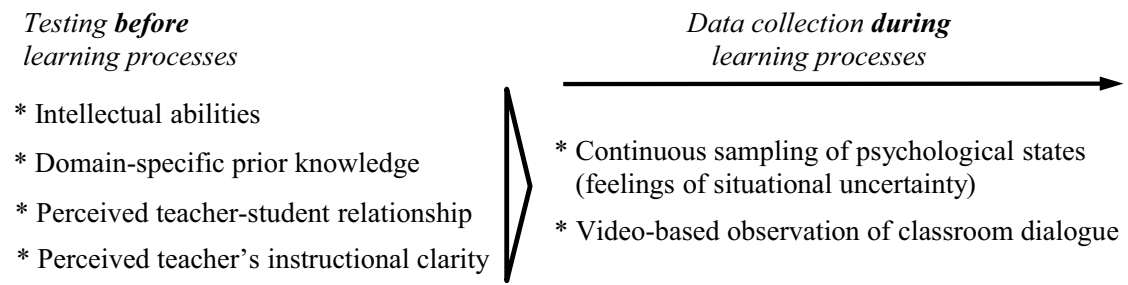

Fig. 1 Research design of the present study 
student $(\mathrm{M}=37.27, \mathrm{SD}=3.88$, $\mathrm{Min}=25$, Max $=43)$. Total scores do not deviate systematically between the two classes.

Domain-specific prior knowledge was measured using two dimensions of the "Wirtschaftskundlicher Bildungs-Test" (WBT; Beck and Krumm 1998), an adoption of the "Test of Economic Literacy" (Soper and Walstad 1987). In Germany, this instrument is widely employed to measure economic literacy among commercial trainees (c.f. Beck et al. 2001). The WBT stands as a valid diagnostic tool that assesses individual knowledge and understanding of essential concepts and principles in economic decisionmaking. Expert ratings from economic scientists and teachers corroborate its content validity. Criterion-related validity reaches $\mathrm{r}=-0.34$ when measured against school grades (which range from $1=$ "very good" to $6=$ "inadequate" in the German school system; Beck and Krumm 1998). In a recent validation study with university students (Förster et al. 2012), WBT sum-scores correlated only modestly with measures of general intelligence (ranging from $r=0.20$ to 0.34 ), but were substantially predicted by a completed commercial apprenticeship $(B=0.52)$. Thus, we can assume that WBT-test scores are loosely related to but analytically distinct from fluid components of intelligence, such as numerical or figural reasoning, which in turn are strongly associated with individual working memory capacity (Engle et al. 1999; Jaeggi et al. 2008). Instead, they mainly tap crystalline components that are reflected in vocabulary, know-how and economic reasoning abilities accumulated through previous education and experience in the domain of economics (see also Backes-Gellner et al. 2011). With its focus on essential economic concepts and principles, the full version of the WBT covers four dimensions, including macro-economic issues and international relations. But in order to assess prior knowledge relevant to the working and learning tasks of industrial clerks in training, we only employed two of these dimensions in the present study: "Basics" (covering concepts such as scarcity, opportunity costs, productivity, business systems, and performance incentives) and "Microeconomics" (focusing on markets and pricing, competition, supply and demand, etc.). The 25 tasks representing these dimensions vary with respect to difficulty levels and can be assigned to Bloom's (1956) taxonomy of educational objectives, which also guided our distinctions of more or less cognitively demanding verbal interactions. Five subsets of tasks pertain to factual knowledge (5 tasks, $\mathrm{M}=3.18, \mathrm{SD}=1.13$, $\mathrm{Min}=0, \mathrm{Max}=5$ ), comprehension (7 tasks, $\mathrm{M}=3.0$, $\mathrm{SD}=1.32$, Min $=0, \mathrm{Max}=6)$, application ( 8 tasks, $\mathrm{M}=4.59, \mathrm{SD}=1.55$, $\mathrm{Min}=1$, $\mathrm{Max}=8$ ), analysis (2 tasks, $\mathrm{M}=0.49, \mathrm{SD}=0.68$, $\mathrm{Min}=0, \mathrm{Max}=2$ ), and evaluation (3 tasks, $\mathrm{M}=1.35$, $\mathrm{SD}=0.72$, $\mathrm{Min}=0, \mathrm{Max}=3$ ). Here again, a total score on (micro-)economic literacy was calculated for each participant by summing up achieved scores in all subtests $(\alpha=0.70, \mathrm{M}=12.61$, SD $=3.82$, Min $=4$, Max $=21)$. Class membership does not contribute to explaining varying test scores among the students.

Following standard procedures in the literature (i.e., Preckel et al. 2006), the first step in identifying AAD was to estimate expected WBT scores from attained CFT scores for each student through regression analyses. Intellectual abilities significantly predicted domain-specific prior knowledge $\left(\mathrm{B}=0.359, \mathrm{SE}=0.136, \beta=0.364, \mathrm{R}^{2}=0.133\right.$, $\mathrm{F}(\mathrm{df})=7.181(1), \mathrm{p}=0.01$ ), a finding that resembles Förster et al.s correlational results and indicates that strong intellectual abilities are beneficial but not sufficient for dealing effectively with (micro-)economic issues. By calculating person-specific differences 
between actual and expected achievement scores in a second step, we generated individual measures of $\operatorname{AAD}(\mathrm{M}=0.00, \mathrm{SD}=0.93$, Min $=-1.56$, Max $=1.94)$. This procedure led to an adjusted and continuous measure of prior knowledge, which is strongly associated with the students' WBT scores $\left(\mathrm{r}=0.93^{* * *}\right)$ but independent from their CFT scores $(\mathrm{r}=0.00)$. A positive AAD value thus allows us to conclude that advanced knowledge structures enable the focal person to surpass achievement levels in a test of (micro-)economic literacy that can be expected from classmates with the same general cognitive capabilities.

Teacher-student relationship was assessed by five items that were adopted from PISAConsortium (2006) (e.g. "My teacher is interested in what I have to say"). Learners rated items on a four-point Likert-type scale ( $1=$ "I don't agree at all", $4=$ "I fully agree"). The five items were averaged to a total scale, which showed satisfactory reliability $(\alpha=0.83$; $\mathrm{M}=3.4, \mathrm{SD}=0.44$ ). Ratings of teacher-student relationship deviate slightly between members of different classes (Class 1: $\mathrm{M}=3.23$, $\mathrm{SD}=0.48$; Class 2: $\mathrm{M}=3.57, \mathrm{SD}=0.32$; $\mathrm{p}=0.005)$.

Teacher's instructional clarity was assessed by five items that were adopted from Prenzel (1994) (e.g. "Teacher's presentations and explanations are precise and comprehensible"). Learners rated items on a five-point Likert-type scale $(1=$ "never", $5=$ "very often"). The five items were averaged to a total scale ( $\alpha=0.42 ; \mathrm{M}=3.94, \mathrm{SD}=0.43$ ). Ratings of perceived teacher's instructional clarity do not differ significantly between members of different classes (Class 1: $\mathrm{M}=3.91, \mathrm{SD}=0.45$; Class 2: $\mathrm{M}=3.98, \mathrm{SD}=0.42$; $\mathrm{p}=0.591)$.

Students reported feelings of situational uncertainty every 10 min by using continuous rating scales ranging from 0 (= "I fully disagree") to 100 (= "I fully agree") for the item "I feel uncertain". Because situational experiences represent psychological states that, by definition, emerge from the interplay of both person- and context-bound features (Nezlek and Kuppens 2008), we assessed the extent to which continuous reports of situational uncertainty systematically differ between learners and fluctuate in the course of nine lessons. Intraclass coefficients served to quantify the proportion of between-person variance (ICC1) as well as within-person reliability (ICC2) for repeated measures that are nested in persons (c.f., Hox 2002; Twisk 2006). Between-person variance accounts for $33 \%$ of total variance in the students' situational uncertainty ratings, indicating distinct but not excessive inter-individual differences in level [ICC1 $=\tau^{2} /\left(\tau^{2}+\sigma^{2}\right)=124.31$ / $(124.31+255.38)=0.327]$. Moreover, each single student's self-assessments are strikingly consistent across all measurement points $[\mathrm{ICC} 2=\mathrm{k} \times \mathrm{ICC} 1 /((1+(\mathrm{k}-1) \times \mathrm{ICC} 1)$ with $\mathrm{k}=36$ on average]. Within-person reliability reaches 0.95 for perceived uncertainty, indicating a very high degree of intra-individual stability in the course of nine lessons. Finally, aggregated means for each person suggest that on average and for most of the instructional time, students felt comfortably at ease $(\mathrm{M}=13.86, \mathrm{SD}=11.46$, Min $=0$, Max $=41.35$ ). Total scores deviate only slightly between members of different classes taking account of the possible range from 0 to 100 (Class $1: \mathrm{M}=17.14, \mathrm{SD}=10.68$; Class 2: $\mathrm{M}=10.71, \mathrm{SD}=11.50 ; \mathrm{p}=0.048$ ).

Observational data on verbal interactions were classified by applying a category system that integrates three dimensions of classroom dialogue (see the Additional file 1 for a detailed account including exemplary items). It distinguishes 
- Gestures that are commonly employed to coordinate instructional communication. Students may signal their willingness to contribute by raising a hand and/or calling out. Teachers may call on a student with a hand raised or make cold calls, i.e. request answers from non-volunteering students.

- Types of verbal contributions, which were assigned to the basic moves (Initiation, Response, Follow-up) in recurring IRF sequences.

- Qualities of each move with respect to levels of cognitive elaboration on the subject matter. In line with our theoretical framework, initiation moves include lowerorder and deep-reasoning questions from teachers or students. With regard to the purposes of subsequent analyses, we only coded teacher questions that were directed at a certain student, either by addressing him/her personally or by choosing him/ her from two or more students who all had raised their hands. Response-moves contain students' lower-order and higher-order (i.e., elaborate) answers. The teacher's options to follow up on student answers range-in ascending order of cognitive activation-from short evaluative remarks to correcting reformulations and enriching explanations, and finally, to challenging prompts and responsive questioning techniques.

Two trained raters, who had no information about the students' test scores or selfperceptions, performed the coding independently. Three lessons were double-coded in order to test inter-rater reliabilities for all categories. Results for the obtained measures were all (very) good and are documented in the last column of Table 1 below.

\section{Results}

\section{Descriptive findings on verbal interactions in the vocational classroom}

Table 1 contains descriptive parameters for each coded interactional feature. Minimum, maximum, and mean values as well as standard deviations all relate to aggregate values per person, indicating, for instance, that a student gave on average 3.14 lower-order answers during phases of classroom dialogue. Absolute frequencies (AF) represent summed values for each category in the sample, indicating that, for example, teachers raised a total of 101 (directed) lower-order questions in the dialogic phases of all nine lessons.

As evident from the absolute numbers of codings for teacher-generated and studentgenerated questions, teachers played the dominant role in triggering verbal interactions. Another noteworthy finding is that follow-up moves mainly consisted of short affirmative remarks as well as (affirmative or corrective) remarks that quickly merged into expository talk, indicating that the teachers did not employ a pronounced 'dialogic' mode of instructional communication.

Moreover, dispersion measures for the students' contributions show that learners did not participate equally in whole-class dialogue. In particular, there is at least one student who never raised a hand or made unsolicited contributions, and at least one student who did so 42 times in the course of nine lessons. But students were not equally involved in verbal exchanges either. For example, we find at least one student who never got a chance to contribute even when signalling his/her intentions to do so, and others who were called on by the teacher up to 19 times after raising a hand. 
Table 1 Descriptors and frequencies of verbal interactions during classroom dialogue

\begin{tabular}{|c|c|c|c|c|c|c|c|}
\hline \multicolumn{2}{|l|}{ Category } & Min. p.p. & Max.p.p. & Mean p.p. & SD p.p. & $\mathrm{AF}$ & $\mathrm{ICC}_{3}$ \\
\hline \multicolumn{8}{|l|}{ Coordinating gestures } \\
\hline \multicolumn{2}{|c|}{ Student raises hand or calls out (CG:SHS) } & 0 & 42 & 5.59 & 9.33 & 274 & 0.989 \\
\hline \multicolumn{2}{|c|}{ Teacher calls on a student with hand raised (CG:TC) } & 0 & 19 & 2.57 & 4.21 & 126 & 1.0 \\
\hline \multicolumn{2}{|c|}{ Cold call (on a non-volunteering student) (CG:TCC) } & 0 & 11 & 2.69 & 2.69 & 132 & 1.0 \\
\hline \multicolumn{8}{|c|}{ Quality of verbal interactions } \\
\hline \multirow[t]{2}{*}{ Initiation of teacher } & $\begin{array}{l}\text { Low-order question, directed } \\
\text { (I:TQ-LO) }\end{array}$ & 0 & 12 & 2.06 & 2.47 & 101 & 0.972 \\
\hline & $\begin{array}{l}\text { Deep-reasoning question, } \\
\text { directed (I:TQ-DR) }\end{array}$ & 0 & 12 & 2.04 & 2.75 & 100 & 0.977 \\
\hline \multirow[t]{2}{*}{ Initiation of student } & Lower-order question (I:SQ-LO) & 0 & 2 & 0.18 & 0.49 & 9 & 0.919 \\
\hline & $\begin{array}{l}\text { Deep reasoning question (I:SQ- } \\
\text { DR) }\end{array}$ & 0 & 3 & 0.12 & 0.48 & 6 & 1.0 \\
\hline \multirow{2}{*}{$\begin{array}{l}\text { Response of } \\
\text { student }\end{array}$} & Lower-order answer (R:SA-LO) & 0 & 19 & 3.14 & 3.82 & 154 & 0.974 \\
\hline & Elaborate answer (R:SA-E) & 0 & 16 & 3.18 & 3.85 & 156 & 0.982 \\
\hline \multirow{6}{*}{$\begin{array}{l}\text { Follow-up of } \\
\text { teacher }\end{array}$} & Affirmation (FU:Affirm) & 0 & 13 & 2.41 & 2.93 & 118 & 0.924 \\
\hline & Rejection (FU:Reject) & 0 & 4 & 0.33 & 0.72 & 16 & 1.0 \\
\hline & Reformulation (FU:Reform) & 0 & 2 & 0.12 & 0.44 & 6 & a \\
\hline & $\begin{array}{l}\text { Affirmation/correction cum } \\
\text { direct instruction (FU:DI) }\end{array}$ & 0 & 11 & 1.88 & 2.53 & 92 & 0.964 \\
\hline & Prompt (FU:Prompt) & 0 & 5 & 0.98 & 1.23 & 48 & 0.948 \\
\hline & Responsive questioning (FU:RQ) & 0 & 4 & 0.39 & 0.84 & 19 & 0.961 \\
\hline
\end{tabular}

$\mathrm{N}=49$. Intraclass correlation coefficients $\left(\mathrm{ICC}_{3}\right)$ calculated by two-way mixed models and reported as average values.

$\mathrm{ICC}_{3}=\left(\sigma_{\alpha}^{2}-\sigma_{\varepsilon}^{2}\right) / \sigma_{\alpha}^{2}$, with $\alpha=$ variance between observations and $\varepsilon=$ error variance

p.p. per person, reported as average values, $A F$ absolute frequency in the sample

a FU:Reform did not occur during the three double-coded lessons

\section{Intercorrelations between measured variables}

Table 2 reports intercorrelations between all variables, which were calculated using aggregate measures for each participant $(\mathrm{N}=49)$. We find AAD to be weakly negatively associated with situational uncertainty, indicating that students with advanced prior knowledge tended to feel more confident during instructional communication. Moderate negative correlations between AAD and gender show that male students possessed more prior knowledge in the domain of economics than their female classmates. Individual levels of situational uncertainty do not vary systematically with perceived teacher-student relations or with perceived instructional clarity of the teacher, but AAD is weakly positively correlated with perceived instructional clarity.

Consistent positive correlations of small to moderate size exist between students' levels of AAD and several pedagogically valuable components of classroom dialogue (deepreasoning questions from teachers, elaborate answers from students, prompts and responsive questioning from teachers). In line with theoretical assumptions, AAD is also positively associated with the frequencies in which students raise a hand/call out, are called on by the teachers, and receive affirmative feedback, but not with the frequencies in which students pose lower-order questions and receive dismissive or corrective feedback.

Student's intellectual abilities are not systematically related to any category of verbal interactions. However, several small to moderate negative correlations are apparent between gender and interactional features, indicating more dialogic engagement for 


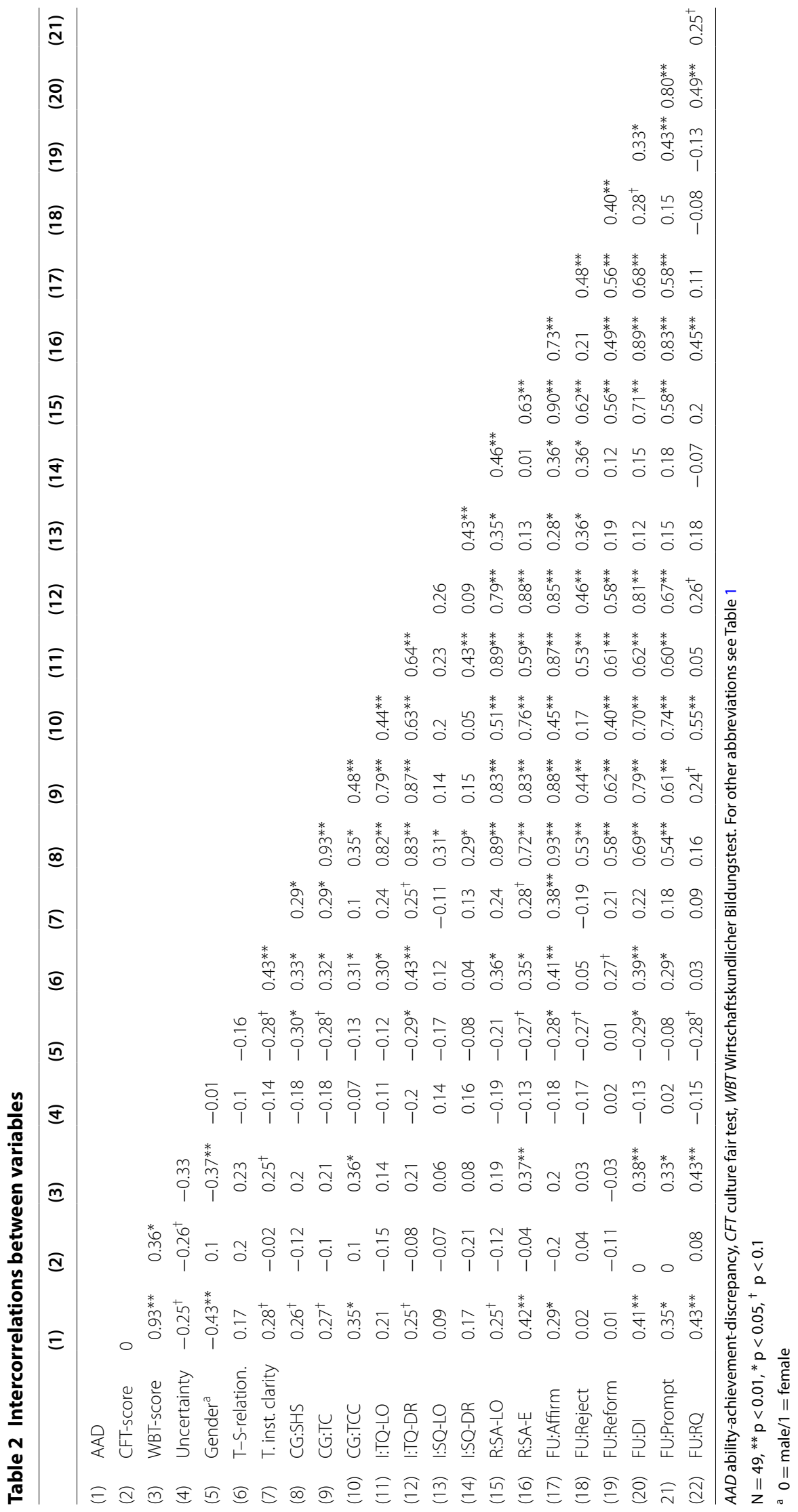


male students than for females. This particularly applies to raising a hand and calling out, being called on after raising a hand, getting deep-reasoning questions, and giving elaborate answers, but also to receiving both positive and negative feedback and being challenged by further reaching questions. Substantial positive associations exist between perceived teacher-student relations and several categories of verbal interactions except for students' own questions, rejecting remarks of the teacher, and teacher's use of responsive questioning techniques. Perceived instructional clarity is also positively, but not always significantly, related to various interactional features. The strongest correlations are found for students' raising a hand, being called on, giving elaborate answers and receiving affirming remarks.

Unsurprisingly, moderate to strong associations exist among several interactional features of classroom dialogue, because they are structurally and topically related to each other (e.g., lower-order questions from teachers and lower-order answers from students). Situational uncertainty, however, does not show significant correlations with any interactional features of classroom dialogue.

\section{Teachers' allocation of speaking turns and tasks among students with different levels of domain-specific prior knowledge}

Tables 3 and 4 provide hierarchical regression results for effects of AAD on the teachers' calling-on strategies, questions, and follow-up moves, with gender as a potential confounding variable. We expected teachers to interact with highly knowledgeable students generally more often ( $\mathrm{H} 1 \mathrm{a})$, and in particular, more often on levels that are cognitively demanding (H1b, c). For the sake of completeness, regressions were run for all interactional features that correlate significantly with AAD (c.f., Table 2).

Findings lend partial support to $\mathrm{H} 1 \mathrm{a}$, as effects of $\mathrm{AAD}$ remain significant for the occurrence of a teacher calling on a non-volunteering student, but not for calling on a student with a hand raised. Nevertheless, the fact that students' AAD alone accounts for

Table 3 Teacher allocation decisions for speaking turns and tasks depending on student levels of domain-specific prior knowledge

\begin{tabular}{|c|c|c|c|c|c|c|c|c|c|}
\hline \multirow[t]{2}{*}{ Variable } & \multicolumn{3}{|c|}{$\begin{array}{l}\text { Teacher calls on student } \\
\text { with hand raised }\end{array}$} & \multicolumn{3}{|c|}{ Cold call } & \multicolumn{3}{|c|}{$\begin{array}{l}\text { Teacher's deep-reasoning } \\
\text { question }\end{array}$} \\
\hline & $b$ & s.e. $b$ & $\beta$ & $b$ & s.e. $b$ & $\beta$ & $b$ & s.e. $b$ & $\beta$ \\
\hline \multicolumn{10}{|l|}{ Step 1} \\
\hline Constant & $2.57^{* *}$ & 0.59 & & $2.69^{* *}$ & 0.37 & & $2.04^{* *}$ & 0.38 & \\
\hline$A A D$ & 1.14 & 0.59 & $0.27^{\dagger}$ & 0.95 & 0.37 & $0.35^{*}$ & 0.70 & 0.39 & $0.25^{\dagger}$ \\
\hline$R^{2}(F, p)$ & \multicolumn{3}{|c|}{$0.073(3.717, p=0.06)$} & \multicolumn{3}{|c|}{$0.125(6.685, p=0.013)$} & \multicolumn{3}{|c|}{$0.064(3.232, p=0.079)$} \\
\hline \multicolumn{10}{|l|}{ Step 2} \\
\hline Constant & $5.48^{*}$ & 2.31 & & 2.45 & 1.47 & & $4.12^{* *}$ & 1.51 & \\
\hline AAD & 0.77 & 0.65 & 0.18 & 0.98 & 0.41 & $0.36^{*}$ & 0.43 & 0.43 & 0.16 \\
\hline Gender & -1.76 & 1.35 & -0.20 & 0.15 & 0.86 & 0.03 & -1.26 & 0.88 & -0.22 \\
\hline$R^{2}$ & \multicolumn{3}{|c|}{0.106} & \multicolumn{3}{|c|}{0.125} & \multicolumn{3}{|l|}{0.104} \\
\hline$\Delta R^{2}(\Delta F, p)$ & \multicolumn{3}{|c|}{$0.033(1.694, p=0.20)$} & \multicolumn{3}{|c|}{$<0.001(0.03, p=0.863)$} & \multicolumn{3}{|c|}{$0.04(2.021, p=0.162)$} \\
\hline
\end{tabular}

$A A D$ ability-achievement discrepancy

$\mathrm{N}=49,{ }^{* *} \mathrm{p}<0.01,{ }^{*} \mathrm{p}<0.05,{ }^{\dagger} \mathrm{p}<0.1$

a $0=$ male $/ 1=$ female 
Table 4 Teacher follow-up moves depending on student levels of domain-specific prior knowledge

\begin{tabular}{|c|c|c|c|c|c|c|c|c|c|c|c|}
\hline \multirow[t]{2}{*}{ Variable } & \multicolumn{3}{|c|}{ Affirmation } & \multicolumn{3}{|c|}{$\begin{array}{l}\text { Affirmation/correction } \\
\text { cum direct instruction }\end{array}$} & \multicolumn{2}{|l|}{ Prompt } & \multicolumn{3}{|c|}{$\begin{array}{l}\text { Responsive } \\
\text { questioning }\end{array}$} \\
\hline & $b$ & s.e. $b$ & $\beta$ & $b$ & s.e. $b$ & $\beta$ & s.e. $b$ & $\beta$ & $b$ & s.e. $b$ & $\beta$ \\
\hline \multicolumn{12}{|l|}{ Step 1} \\
\hline Constant & $2.41^{* *}$ & 0.41 & & $1.88^{* *}$ & 0.33 & & $0.98^{* *} 0.17$ & & $0.39 * *$ & 0.11 & \\
\hline AAD & 0.85 & 0.41 & $0.29^{*}$ & 1.04 & 0.34 & $0.41^{* *}$ & 0.430 .17 & $0.35^{*}$ & 0.36 & 0.11 & $0.43^{* *}$ \\
\hline$R^{2}(F, p)$ & \multicolumn{3}{|c|}{$0.084(4.321, p=0.043)$} & \multicolumn{3}{|c|}{$0.169(9.564, p=0.003)$} & \multicolumn{2}{|c|}{$0.122(6.511, p=0.014)$} & \multicolumn{2}{|c|}{$\begin{array}{l}0.188(10.899 \\
p=0.002)\end{array}$} & \\
\hline \multicolumn{12}{|l|}{ Step 2} \\
\hline Constant & $4.34^{* *}$ & 1.60 & & $3.10^{*}$ & 1.33 & & 0.620 .67 & & 0.71 & 0.44 & \\
\hline AAD & 0.61 & 0.45 & 0.21 & 0.89 & 0.37 & $0.35^{*}$ & 0.480 .19 & $0.39 *$ & 0.32 & 0.12 & $0.39 *$ \\
\hline Gender & -1.17 & 0.94 & -0.19 & -0.74 & 0.78 & -0.14 & 0.220 .39 & 0.09 & -0.20 & 0.26 & -0.11 \\
\hline $\mathrm{R}^{2}$ & \multicolumn{3}{|c|}{0.114} & \multicolumn{3}{|c|}{0.185} & \multicolumn{2}{|r|}{0.128} & \multicolumn{2}{|c|}{0.199} & \\
\hline$\Delta R^{2}(\Delta F, p)$ & \multicolumn{3}{|c|}{$0.03(1.558, p=0.218)$} & \multicolumn{3}{|c|}{$0.016(0.906, p=0.346)$} & \multicolumn{2}{|c|}{$0.006(0.307, p=0.582)$} & \multicolumn{2}{|c|}{$\begin{array}{l}0.011(0.595 \\
p=0.444)\end{array}$} & \\
\hline
\end{tabular}

$A A D$ ability-achievement discrepancy

$\mathrm{N}=49,{ }^{* *} \mathrm{p}<0.01,{ }^{*} \mathrm{p}<0.05,^{\dagger} \mathrm{p}<0.1$

a $0=$ male $/ 1=$ female

about $13 \%$ of explained variance in observed cold callings of the teachers seems remarkable. However, results fail to support $\mathrm{H} 1 \mathrm{~b}$ after controlling for gender. The amount of deep-reasoning questions addressed to a certain student does not systematically depend on his/her levels of prior knowledge. As in the case of calling on a student with a hand raised, findings suggest (weak) additive effects of both student characteristics.

Results corroborate H1c, which posited that teachers follow up on answers of students with advanced prior knowledge more frequently with prompting and responsive questioning techniques. Even after controlling for gender, AAD emerges as a significant predictor of the teachers' communicative behaviours, explaining about 13 and $19 \%$ of variance in these criteria.

It deserves mention that AAD robustly predicts the frequency in which teachers take a student answer as an opportunity to give further instruction on the topic, for example by illustrating different application examples. For simple affirmative remarks, no significant effects are found when controlling for student gender.

\section{Students' contributions to classroom dialogue depending on domain-specific prior knowledge and feelings of uncertainty}

We assumed prior knowledge to predict both the extent and quality of students' active participation in classroom dialogue $(\mathrm{H} 2 \mathrm{a}, \mathrm{b}, \mathrm{c})$. Moreover, we wanted to explore whether prevailing feelings of uncertainty experienced during the communication process might prevent students from participating or hamper the quality of their verbal contributions $(\mathrm{H} 3 \mathrm{a}, \mathrm{b}, \mathrm{c})$. Again we used hierarchical regression models to test these assumptions, considering $A A D$ and situational uncertainty in the first step, adding an interaction term $(\mathrm{AAD} \times \mathrm{SU})$ in the second step, and controlling for gender, perceived teacher-student relationship, and perceived teacher's instructional clarity in the third step (see Table 5). 
Table 5 Moderated regression analysis of students' contributions to classroom dialogue

\begin{tabular}{|c|c|c|c|c|c|c|c|c|c|}
\hline \multirow[t]{2}{*}{ Variable } & \multicolumn{3}{|c|}{$\begin{array}{l}\text { Student raises hand or calls } \\
\text { out }\end{array}$} & \multicolumn{3}{|c|}{$\begin{array}{l}\text { Student's deep-reasoning } \\
\text { question }\end{array}$} & \multicolumn{3}{|c|}{$\begin{array}{l}\text { Student's elaborate } \\
\text { answer }\end{array}$} \\
\hline & $b$ & s.e. $_{b}$ & $\beta$ & $b$ & s.e. $_{b}$ & $\beta$ & $b$ & s.e. $b$ & $\beta$ \\
\hline \multicolumn{10}{|l|}{ Step 1} \\
\hline Constant & $5.59^{* *}$ & 1.31 & & $0.12^{\dagger}$ & 0.07 & & $3.18^{* *}$ & 0.51 & \\
\hline $\mathrm{AAD}$ & 2.10 & 1.36 & 0.23 & 0.11 & 0.07 & 0.22 & 1.58 & 0.53 & $0.41^{* *}$ \\
\hline SU & -1.19 & 1.36 & -0.13 & 0.11 & 0.07 & 0.22 & -0.10 & 0.53 & -0.03 \\
\hline$R^{2}(F, p)$ & \multicolumn{3}{|c|}{$0.081(2.034, p=0.142)$} & \multicolumn{3}{|c|}{$0.073(1.816, p=0.174)$} & \multicolumn{3}{|c|}{$0.174(4.859, p=0.012)$} \\
\hline \multicolumn{10}{|l|}{ Step 2} \\
\hline Constant & $5.49^{* *}$ & 1.37 & & $0.15^{*}$ & 0.07 & & $3.26^{* *}$ & 0.54 & \\
\hline $\mathrm{AAD}$ & 2.00 & 1.43 & 0.21 & 0.14 & 0.07 & $0.28^{\dagger}$ & 1.65 & 0.56 & $0.43^{* *}$ \\
\hline SU & -1.25 & 1.40 & -0.13 & 0.12 & 0.07 & $0.25^{\dagger}$ & -0.06 & 0.55 & -0.01 \\
\hline$A A D \times S U$ & -0.42 & 1.55 & -0.04 & 0.11 & 0.08 & 0.21 & 0.30 & 0.61 & 0.07 \\
\hline$R^{2}$ & \multicolumn{3}{|l|}{0.083} & \multicolumn{3}{|l|}{0.112} & \multicolumn{3}{|l|}{0.179} \\
\hline$\Delta R^{2}(\Delta F, p)$ & \multicolumn{3}{|c|}{$0.002(0.074, p=0.787)$} & \multicolumn{3}{|c|}{$0.039(1.990, p=0.165)$} & \multicolumn{3}{|c|}{$0.004(0.238, p=0.628)$} \\
\hline \multicolumn{10}{|l|}{ Step 3} \\
\hline Constant & $12.31^{*}$ & 5.58 & & 0.19 & 0.31 & & $4.69^{*}$ & 2.21 & \\
\hline $\mathrm{AAD}$ & 0.66 & 1.52 & 0.07 & 0.12 & 0.08 & 0.25 & 1.30 & 0.60 & $0.34^{*}$ \\
\hline SU & -1.24 & 1.35 & -0.13 & 0.12 & 0.07 & 0.25 & -0.02 & 0.54 & -0.01 \\
\hline $\mathrm{AAD} \times \mathrm{SU}$ & 0.09 & 1.58 & 0.01 & 0.11 & 0.09 & 0.20 & 0.42 & 0.63 & 0.10 \\
\hline Gender & -4.05 & 3.20 & -0.21 & -0.02 & 0.18 & -0.02 & -0.85 & 1.27 & -0.11 \\
\hline T-S-relationship & 2.21 & 1.42 & 0.24 & -0.01 & 0.08 & -0.01 & 1.02 & 0.56 & $0.26^{+}$ \\
\hline T. instruct. clarity & 0.85 & 1.50 & 0.09 & 0.04 & 0.08 & 0.09 & 0.14 & 0.60 & 0.04 \\
\hline$R^{2}$ & \multicolumn{3}{|l|}{0.208} & \multicolumn{3}{|l|}{0.120} & \multicolumn{3}{|l|}{0.269} \\
\hline$\Delta R^{2}(\Delta F, p)$ & \multicolumn{3}{|c|}{$0.126(2.220, p=0.100)$} & \multicolumn{3}{|c|}{$0.008(0.122, p=0.947)$} & \multicolumn{3}{|c|}{$0.090(1.727, p=0.176)$} \\
\hline
\end{tabular}

$A A D$ ability-achievement discrepancy, SU situational uncertainty

$\mathrm{N}=49,{ }^{* *} \mathrm{p}<0.01,{ }^{*} \mathrm{p}<0.05,^{\dagger} \mathrm{p}<0.1$

a $0=$ male $/ 1=$ female

No significant moderating effects of situational uncertainty emerge for any of the interactional features reported in the Table, which leads us to reject hypotheses 3a to 3c.

Regarding the central variable of our study, individual levels of AAD do not significantly predict the frequency in which a student signals willingness to take part in dialogic exchanges when controlling for gender, teacher-student relations, and instructional clarity (H2a). Although regression results are not significant, male students as well as students who perceive teacher-student relations to be emotionally warm and supportive tend to be prevalent in the group of volunteers.

The amount of deep-reasoning questions posed by the learners is not significantly affected by AAD either (H2b), even though small effects in the expected direction are evident in the present sample. Prevailing feelings of uncertainty seem to be additionally conducive to raising questions that aim at a deeper understanding of subject matter, but again, effect sizes are modest and findings cannot be generalised with a sufficiently low error probability.

Conforming to theoretical assumptions, however, individual levels of AAD robustly and substantially predict the occurrence of elaborate answers given by a student (H2c). The final regression model, which also includes estimates for influences of gender, teacher-student relationship, teacher's instructional clarity, situational uncertainty, 
and potential interactions of AAD and situational uncertainty, explains about $27 \%$ of inter-individual differences in giving such well-reasoned answers. In addition to AAD, perceived teacher-student relations (approaching significance at $\mathrm{p}=0.079$ ), positively affect student's elaborate answers in this model.

\section{Discussion and conclusions}

Recurring descriptive accounts of the prevalence of whole-class dialogue among instructional patterns in commercial vocational schools in Germany marked the starting point of our study. We aimed to extend previous research by elucidating pedagogically valuable dialogic practices that facilitate students' conceptual understanding and development, and by empirically investigating factors that promote or hinder student engagement in these practices. Our main focus was on prior knowledge in the domain discussed, because prior knowledge differences count among the prime sources of heterogeneity among vocational students in Germany. However, with survey studies suggesting a decisive role of communication apprehension, we also wanted to explore if situational feelings of uncertainty in ongoing verbal interactions moderate the knowledge-engagement relationship. Last but not least, statistical analyses included several control variables in order to rule out confounding and suppressor effects on the extent or quality of verbal interactions.

The study employed a longitudinal, multi-method design that combined observational data from video recordings on nine consecutive lessons about Economic Business Processes in two classes, preceding tests on intellectual abilities and economic literacy, questionnaire reports of teacher-student-relations and instructional clarity, as well as Continuous State Sampling during instructional activities. We used individual AAD as a "distilled" measure of domain-specific prior knowledge by partialling out general intelligence. Furthermore, we drew on continuous-state reports of uncertainty as a measure with closer proximity to action regulation than retrospective or global self-assessments.

Hierarchical regression analyses provide substantial but non-conclusive evidence for the assumption that getting opportunities to engage in valuable components of classroom dialogue depend on individual levels of domain-specific prior knowledge. Contrary to our hypothesis, teachers do not concede more speaking turns to highly knowledgeable students when choosing a person from a number of students who raise their hands. But in line with theoretical considerations, differential teacher treatment exists with regard to cold calling strategies as well as demanding follow-up techniques, even after controlling for student gender. That is, when requesting contributions from non-volunteering students, teachers preferably address persons with advanced knowledge structures in the domain of interest. Furthermore, teachers follow up on their answers more frequently with prompting and responsive questioning techniques, thereby sustaining the pressure on highly knowledgeable students to process subject matter actively and deeply. For instance, they invite them to refine or justify their proposals, confront them with changing scenarios in which to re-evaluate their decisions, or ask them to draw inferences from their solutions.

Moderated regression analyses that were run to examine main and combined effects of prior knowledge and situational uncertainty on the communicative behaviours of students offer mixed results. Consistent with theoretical assumptions, advanced knowledge 
structures substantially affect the quality of verbal contributions. We had posited a conceptual-level correspondence between the learners' mental models of a given domain and their contributions to dialogic exchanges and find that individual AAD robustly predicts the amount of well-founded arguments and thorough explanations put forth in the interaction process. Positive teacher-student relations add to these effects. This result underscores the functional role of prior knowledge in seizing opportunities to engage in pedagogically valuable components of classroom dialogue, particularly if dialogic exchanges are framed by an emotionally warm, encouraging, and supportive learning environment. Complementing the picture, AAD is positively associated with the amount of deep-reasoning questions a student poses, even though this finding is confined to the present sample and regression coefficients are small after controlling for other potential influences. In view of the fact that the vast majority of observed initiation moves were made by the teachers, we would expect even more compelling evidence of the proposed conceptual-level correspondence in dialogic practices that are structurally more open for student-student interaction, and thus for student-generated questions (e.g., small group discussions; Seifried and Sembill 2005; Wuttke 2012).

However, findings do not corroborate the assumption that highly knowledgeable students in vocational classrooms are generally more 'talkative' than students with comparably poor knowledge on the subject at hand. Instead they imply that the frequency in which students raise a hand or call out tend to be more dependent on gender and perceived teacher-student relations.

The absence of significant interaction effects between AAD and situational uncertainty in all regression models suggest that feeling unsure does not systematically keep students from participating in classroom dialogue and does not impair the quality of their contributions. However, there are some restrictive conditions regarding the data and the instructional arrangement that should be carefully considered before discarding the underlying theoretical assumptions. From a statistical point of view, strong ground effects that we found in students' continuously reported uncertainty levels markedly reduce chances for this variable to explain varying communicative behaviours. From a methodological point of view, correlations between questionnaire items on both feelings and behavioural consequences (which have been employed in previous survey studies) are typically higher than between self-reported and observational measures (e.g. Campbell and Fiske 1959). From a conceptual point of view, it should be noted that classroom dialogue leaves more decisional freedom to students to take part or retreat than many other instructional arrangements, despite irregular events of a teacher adopting cold-calling strategies. Consequently, even those students who are generally anxious to express their ideas in front of their classmates (i.e., those affected by trait-like or generalised context communication apprehension) hardly run the risk of encountering acute feelings of situational uncertainty if they choose to strictly avoid situations in which they have to speak (e.g. MacIntyre 2007). We thus expect that the assumed moderating role of situational uncertainty for effects of prior knowledge on verbal contributions would be more visible in phases of instructional communication that cannot be evaded, for example when presenting the results of small group work in front of classmates.

Finally, it deserves mention that in contrast to several previous studies, only weak effects of student gender appear in our regression models. We believe that once again, 
domain-specificity aids to explain this finding. It might well be that curricular and job contents for industrial clerks in training are less fraught with gender stereotypes that could shape vocational students' communicative behaviour than, for instance, other subject matter such as physics in general education settings (c.f. Kessels 2005). To summarise, our analyses suggest that domain-specific prior knowledge is not an indispensable prerequisite to 'somehow' engage in classroom dialogue. But it is a decisive factor for participation and involvement in those dialogic practices that trigger and perpetuate deep elaboration of learning contents. We were also able to demonstrate that these effects are not confounded with intellectual abilities, which bear no systematic relation with any of the observed interactional features. Generalisability is nevertheless restricted by the small sample and the focal content domain.

We further conclude that valid measurement of relevant student aptitudes for engaging in verbal interactions (still) poses a formidable challenge to empirical investigations, which certainly contributes to the broad neglect of these determinants in previous research. Specifically in our study, it stands to question if alternative tests of economic literacy are even more suited to assess domain-specific prior knowledge of commercial trainees than the two subdimensions of the WBT ("Basics" and "Microeconomics") that we have employed. With general regard to explaining teachers' communicative behaviours, it might be fruitful in future studies to use measures of both tested and expected levels of prior knowledge and intelligence in order to examine degrees of convergence and to investigate in a comparative manner if and to what extent teacher beliefs are more predictive of differential treatment than the learners' factual cognitive prerequisites. Furthermore, profiling approaches to identify different types of learners, considering cognitive and motivational prerequisites simultaneously, might offer insights into students' differing strategies of participation.

Despite its limitations, our study points to a pedagogical dilemma that deserves attention from every reflective professional. Assigning cognitively demanding tasks mainly to students with advanced knowledge undoubtedly helps to proceed swiftly in the curriculum and to avoid (allegedly) confusing detours in dialogic sequences. Yet it also reduces chances for students with knowledge deficits to deal extensively with learning contents and to learn from errors, and thus to enhance conceptual understanding and development on their part. Our results suggest that it can be beneficial to integrate in situ analyses of verbal interactions into research on the so-called Matthew effect, which predominantly relies on standardised pre- and post-tests of academic achievement in order to examine varying learning gains between the students as dependent on prior knowledge (cf. Sideridis 2011). Differences concerning student participation and involvement in communicative practices might aid in identifying how processes of instructional communication enhance or reduce such differences in learning gains.

\section{Additional file}

Additional file 1. Instruments and operationalisation of constructs. 


\section{Authors' contributions}

TK designed the study and handled the data collection. TK and JW both conceptualized the aim and structure of the research paper. Furthermore, both authors managed the literature searches and statistical analyses and wrote the paper. Both authors read and approved the final manuscript.

\section{Competing interests}

The authors declare that they have no competing interests.

Received: 1 July 2015 Accepted: 23 September 2015

Published online: 13 October 2015

\section{References}

Airasian PW (1997) Classroom assessment. McGraw-Hill, New York

Backes-Gellner U, Schneider MR, Veen S (2011) Effect of workforce age on quantitative and qualitative organizational performance: conceptual framework and case study evidence. Organ Stud 32(8):1103-1121

Barry S, Lazarte AA (1998) Evidence for mental models: how do prior knowledge, syntactic complexity, and reading topic affect inference generation in a recall task for nonnative readers of Spanish? Mod Lang J 82(2):176-193

Baumert J, Kunter M, Blum W, Brunner M, Voss T, Jordan A, Klusmann U, Krauss S, Neubrand M, Tsaj JM (2010) Teachers' mathematical knowledge, cognitive activation in the classroom, and student progress. Am Educ Res J 47(1):133-180

Beck K, Krumm V (1998) Wirtschaftskundlicher Bildungstest (WBT) [German adoption of the Test of Economic Literacy from Soper and Walstad, 1987]. Hogrefe, Göttingen

Beck K, Krumm V, Dubs R (2001) WBT - Wirtschaftskundlicher Bildungstest. In: Sarges W, Wottawa H (eds) Handbuch wirtschaftspsychologischer Testverfahren. Pabst, Lengerich, pp 559-562

Berland LK, Reiser BJ (2009) Making sense of argumentation and explanation. Sci Educ 93(1):26-55

Bloom, BS, Engelhart MD, Furst EJ, Hill WH, Krathwohl DR (1956) Taxonomy of educational objectives: the classification of educational goals. Handbook I: cognitive domain. David McKay Company, New York

Bohlmann NL, Weinstein RS (2013) Classroom context, teacher expectations, and cognitive level: predicting children's math ability judgements. J Appl Dev Psychol 34(6):288-298

Bourhis J, Allen M, Bauman I (2006) Communication apprehension: issues to consider in the classroom. In: Gayle BM, Preiss RW, Burrell N, Allen M (eds) Classroom communication and instructional processes: advances through meta-analysis. Lawrence Erlbaum Associates, Mahwah, pp 211-227

Byrne M, Flood B, Shanahan D (2012) A qualitative exploration of oral communication apprehension. Acc Educ 21(6):565-581

Campbell DT, Fiske DW (1959) Convergent and discriminant validation by the multitrait-multimethod matrix. Psychol Bull 56(2):81-105

Chesebro JL (2003) Effects of teacher clarity and nonverbal immediacy on student learning, receiver apprehension, and affect. Commun Educ 52(2):135-147

Chin C (2006) Classroom interaction in science: teacher questioning and feedback to students' responses. Int J Sci Educ 28(11):1315-1346

Chin C, Brown DE (2000) Learning in science: a comparison of deep and surface approaches. J Res Sci Teach 37(2):109-138

Chin C, Osborne J (2008) Students' questions: a potential resource for teaching and learning science. Stud Sci Educ 44(1):1-39

Costa J, Caldeira H, Gallastegui JR, Otero J (2000) An analysis of question asking on scientific texts explaining natural phenomena. J Res Sci Teach 37(6):602-614

Csíkszentmihályi M, Larson R (1987) Validity and reliability of the experience-sampling method. J Nerv Ment Dis 175(9):526-536

Cullen R (2002) Supportive teacher talk: the importance of the F-move. ELT J 56(2):117-127

De Leeuw N, Chi MTH (2003) Self-explanation: enriching a situation model or repairing a domain model? In: Sinatra G, Pintrich P (eds) Intentional conceptual change. Erlbaum, Hillsdale, pp 55-78

Ding M, Li X, Piccolo D, Kulm G (2007) Teacher interventions in cooperative learning mathematics classes. J Educ Res 100(3):162-175

Eccles JS, Roeser RW (2012) School influences on human development. In: Mayes L, Lewis M (eds) The Cambridge handbook of environment in human development. Cambridge University Press, Cambridge, pp 259-283

Engle RW, Tuholski SW, Laughlin JE, Conway AR (1999) Working memory, short-term memory, and general fluid intelligence: a latent-variable approach. J Exp Psychol Gen 128(3):309-331

Fassinger PA (1996) Professors' and students' perceptions of why students participate in class. Teach Sociol 24(1):25-33

Fassinger PA (2000) How classes influence students' participation in college classrooms. J Classr Interact 35(2):38-47

Förster M, Happ R, Zlatkin-Troitschanskaia O (2012) Valide Erfassung des volkswirtschaftlichen Fachwissens von Studierenden der Wirtschaftswissenschaften und der Wirtschaftspädagogik-eine Untersuchung der diagnostischen Eignung des Wirtschaftskundlichen Bildungstests (WBT). [Valid measurement of university students' economic content knowledge - an investigation of the diagnostic suitability of the German "Wirtschaftskundlicher Bildungstest" (an equivalent of the American Test of Economic Literacy)]. bwp@—Berufs- und Wirtschaftspädagogik online 22

Gardner CT, Milne MJ, Stringer CP, Whiting RH (2005) Oral and written communication apprehension in accounting students: curriculum impacts and impacts on academic performance. Account Educ 14(3):313-336 
Gayle BM, Preiss RW, Allen M (2006) How effective are teacher-initiated classroom questions in enhancing student learning? In: Gayle BM, Preiss RW, Burrell N, Allen M (eds) Classroom communication and instructional processes: advances trough meta-analysis. Lawrence Erlbaum Associates, Mahwah, pp 279-294

Götzl M, Jahn RW, Held G (2013) Bleibt alles anders?! Sozialformen, Unterrichtsphasen und echte Lernzeit im kaufmännischen Unterricht. [Will everything stay different?! Social forms, teaching phases and genuine learning time in training for commercial occupations]. bwp@ - Berufs- und Wirtschaftspädagogik online 24

Graesser AC, Person NK (1994) Question asking during tutoring. Am Educ Res J 31 (1):104-137

Hailikari T, Nevgi A, Komulainen E (2008) Academic self-beliefs and prior knowledge as predictors of student achievement in mathematics: a structural model. Educ Psychol 28(1):59-71

Hattie J, Timperly H (2007) The power of feedback. Rev Educ Res 77(1):81-112

Hennigsen M, Stein MK (1997) Mathematical tasks and student cognition: classroom-based factors that support and inhibit high-level mathematical thinking and reasoning. J Res Math Educ 28(5):524-549

Hines CV, Cruickshank DR, Kennedy JJ (1985) Teacher clarity and its relationship to student achievement and satisfaction. Am Educ Res J 22(1):87-99

Hmelo-Silver CE (2004) Problem-based learning: what and how do students learn? Educ Psychol Rev 16(3):235-266

Howard JR, Baird R (2000) The consolidation of responsibility and students' definitions of situation in the mixed-age college classroom. J High Educ 71(6):214-234

Howe C, Abedin M (2013) Classroom dialogue: a systematic review across four decades of research. Camb J Educ 43(3):325-356

Hox J (2002) Multilevel analysis: techniques and applications. Lawrence Erlbaum Associates, London

Hyde CA, Ruth BJ (2002) Multicultural content and class participation: do students self-censor? J Soc Work Educ 38(2):241-256

Jaeggi SM, Buschkuehl M, Jonides J, Perrig WJ (2008) Improving fluid intelligence with training on working memory. Proc Natl Acad Sci 105(19):6829-6833

Jones S, Dindia K, Tye S (2006) Sex equity in the classroom: do female students lose the battle for teacher attention? In: Gayle BM, Preiss RW, Burrell N, Allen M (eds) Classroom communication and instructional processes: advances through meta-analysis. Lawrence Erlbaum Associates, Mahwah, pp 185-210

Jurik V, Gröschner A, Seidel T (2013) How student characteristics affect girls'and boys'verbal engagement in physics instruction. Learn Instr 23:33-42

Kärner T (2015) Erwartungswidrige Minderleistung und Belastung im kaufmännischen Unterricht: Analyse pädagogischer, psychologischer und physiologischer Aspekte [Underachievement and stress in vocational business education: analysis of pedagogical, psychological, and physiological aspects]. Lang, Frankfurt am Main

Karp DA, Yoels WC (1976) The college classroom: some observations on the meaning of student participation. Sociol Soc Res 60(4):421-439

Kessels U (2005) Fitting into the stereotype: How gender-stereotyped perceptions of prototypic peers relate to liking for school subjects. Eur J Psychol Educ 20(3):309-323

Kintsch W (2005) An overview of top-down and bottom-up effects in comprehension: the Cl perspective. Discourse Process 39(2-3):125-128

Kluger AN, de Nisi A (1996) The effects of feedback interventions on performance: a historical review, a meta-analysis, and a preliminary feedback intervention theory. Psychol Bull 119(2):254-284

Leeman J (2003) Recasts and second language development: beyond negative evidence. Stud Second Lang Acquis 25(1):37-63

Lipowsky F, Rakoczy K, Pauli C, Reusser K, Klieme E (2007) Gleicher Unterricht: gleiche Chancen für alle? Die Verteilung von Schülerbeiträgen im Klassenunterricht. [The Same Instruction The Same Chances for Everyone? The Distribution of Contributions from Students in Whole-Class Discussions.]. Unterrichtswissenschaft 35(2):125-147

Loyens SM, Gijbels D (2008) Understanding the effects of constructivist learning environments: introducing a multidirectional approach. Instr Sci 36(5-6):351-357

Lyle S (2008) Dialogic teaching: discussing theoretical contexts and reviewing evidence from classroom practice. Lang Educ 22(3):222-240

Lyster R, Mori H (2006) Interactional feedback and instructional counterbalance. Stud Second Lang Acquis 28(2):269-300

Lyster R, Saito K (2010) Interactional feedback as instructional input: a synthesis of classroom SLA research. Lang Interact Acquis 1:276-297

Maclntyre PD (2007) Willingness to communicate in the second language: understanding the decision to speak as a volitional process. Mod Lang J 91(4):564-576

McCroskey JC (2012) Oral communication apprehension: a reconceptualization. In: Burgoon M (ed) Communication yearbook 6. Routledge, New York, pp 136-170

Metcalf KK (1992) The effects of a guided training experience on the instructional clarity of preservice teachers. Teach Teach Educ 8(3):275-286

Miyake N, Norman DA (1979) To ask a question, one must know enough to know what is not known. J Verbal Learn Verbal Behav 18(3):357-364

Mottet TP, Martin MM, Myers SA (2004) Relationships among perceived instructor verbal approach and avoidance relational strategies and students' motives for communicating with their instructor. Commun Educ 53(1):116-122

Murphy PK, Wilkinson IAG, Soter AO, Hennessey MN (2009) Examining the effects of classroom discussion on students' comprehension of text: a meta-analysis. J Educ Psychol 101(3):740-764

Nezlek JB, Kuppens P (2008) Regulating positive and negative emotions in daily life. J Pers 76(3):561-580

Nussbaum ME (2008) Collaborative discourse, argumentation, and learning: preface and literature review. Contemp Educ Psychol 33(3):345-359

Özerk K (2001) Teacher-student verbal interaction and questioning, class size and bilingual students' academic performance. Scand J Educ Res 45(4):353-367

Phoenix CY (1987) Get them involved! styles of high- and low-rated teachers. Coll Teach 35(1):13-15 
PISA-Consortium (2006) Dokumentation der Erhebungsinstrumente. PISA-Konsortium Deutschland (Hrsg.), [Documentation of survey instruments. PISA-Consortium Germany (Eds.)]. Waxmann, Münster

Preckel F, Holling H, Vock M (2006) Academic underachievement: relationship with cognitive motivation, achievement motivation, and conscientiousness. Psychol Sch 43(3):401-411

Prenzel M (1994) Fragebogen zu "Motivationalen Bedingungen"und zu "Motivationalen Prozessen beim Lernen"[Questionnaire for "Motivational conditions" and "Motivational processes during learning", unpublished manuscript], Regensburg, Germany

Renaud RD, Murray HG (2007) The validity of higher-order questions as a process indicator of educational quality. Res High Educ 48(3):319-351

Reyes MR, Brackett MA, Rivers SE, White M, Salovey P (2012) Classroom emotional climate, student engagement, and academic achievement. J Educ Psychol 104(3):700-712

Reznitskaya A, Anderson RC, McNurlen B, Nguyen-Jahiel K, Archodidou A, Kim S (2001) Influence of oral discussion on written argument. Discourse Process 32(2-3):155-175

Rocca KA (2009) Participation in the college classroom: the impact of instructor immediacy and verbal aggression. J Classr Interact 43(2):22-33

Rocca KA (2010) Student participation in the college classroom: an extended multidisciplinary literature review. Commun Educ 59(2):185-213

Rost DH, Hanses P (1997) Wer nichts leistet, ist nicht begabt? Zur Identifikation hochbegabter Underachiever durch Lehrkräfte [Not achieving - not gifted? About the identification of gifted underachievers by teacher-ratings]. Zeitschrift für Entwicklungspsychologie und Pädagogische Psychologie XXIX(2):167-177

Rubie-Davies CM (2007) Classroom interactions: exploring the practices of high and low expectation teachers. Br J Educ Psychol 77(2):289-306

Scardamalia M, Bereiter C (1992) Text-based and knowledge-based questioning by children. Cognit Instr 9(3):177-199

Seeber S (2009) Differente Schülervoraussetzungen, Lernmilieu und Lernerfolg in beruflichen Bildungsgängen. [Diverging prerequisites of students, learning settings and learning success in courses of vocational education]. In: van Buer J, Wagner C (eds) Qualität von Schule. Ein kritisches Handbuch. Peter Lang, Frankfurt am Main, pp 469-480

Seifried J, Sembill D (2005) Schülerfragen: ein brachliegendes didaktisches Feld. Zeitschrift für Berufs- und Wirtschaftspädagogik 101(2):229-245

Seifried J, Grill L, Wagner M (2006) Unterrichtsmethoden in der kaufmännischen Unterrichtspraxis [Instructional methods in business education]. Wirtschaft und Erziehung 58(7-8):236-241

Sembill D (1984) Modellgeleitete Interaktionsanalysen im Rahmen einer forschungsorientierten Lehrerausbildung—am Beispiel von Untersuchungen zum „Kaufvertrag“[Model-based interaction analysis within the scope of research based teacher education — examplified by investigations on the topic'purchase agreement']. Berichte des Seminars für Wirtschaftspädagogik der Georg-August-Universität Göttingen, Band 7, Göttingen

Sembill D (1987) Wirtschaftslehreunterricht: Einige Forschungsergebnisse zum Zusammenhang von Verbalurteilen und Handeln am Beispiel der Unterrichtseinheit „Kaufvertrag"[Economics education: some research findings to the association between verbal judgements and actions by the example of the teaching unit 'purchase agreement']. Zeitschrift für Berufs- und Wirtschaftspädagogik 83(3):213-232

Sembill D, Wolf KD, Wuttke E, Schumacher L (2002) Self-organized learning in vocational education-foundation, implementation, and evaluation. In: Beck K (ed) Teaching-learning processes in vocational education: foundations of modern training programmes. Peter Lang, Frankfurt am Main, pp 267-295

Sembill D, Seifried J, Dreyer K (2008) PDAs als Erhebungsinstrument in der beruflichen Lernforschung: ein neues Wundermittel oder bewährter Standard? Eine Replik auf Henning Pätzold. [PDAs as a tool for data collection in adult education research—New panacea or approved standard?] Empirische Pädagogik 22(1):64-77

Sideridis GD (2011) Exploring the presence of Matthew effects in learning disabilities. J Learn Disabil 44(5):399-401

Simonds CJ (1997) Classroom understanding: an expanded notion of teacher clarity. Commun Res Rep 14(3):279-290

Sinclair JM, Brazil D (1982) Teacher talk. Oxford University Press, Oxford

Slavin RE (2011) Instruction based on cooperative learning. In: Mayer RE, Alexander PA (eds) Handbook of research on learning and instruction. Taylor \& Francis, New York, pp 344-360

Smith H, Higgins S (2006) Opening classroom interaction: the importance of feedback. Camb J Educ 36(4):485-502 Soper JCh, Walstad WB (1987) Test of economic literacy, 2nd edn. Joint Council on Economics Education, New York

Südkamp A, Kaiser J, Möller J (2012) Accuracy of teachers' judgments of students' academic achievement: a meta-analysis. J Educ Psychol 104(3):743-762

Taboada A, Guthrie JT (2006) Contributions of student questioning and prior knowledge to construction of knowledge from reading information text. J Lit Res 38(1):1-35

Twisk JWR (2006) Applied multilevel analysis: a practical guide. Cambridge University Press, Cambridge

van Blankenstein FM, Dolmans DH, van der Vleuten CP, Schmidt HG (2011) Which cognitive processes support learning during small-group discussion? The role of providing explanations and listening to others. Instr Sci 39(2):189-204

von Aufschnaiter C, Erduran S, Osborne J, Simon S (2008) Arguing to learn and learning to argue: case studies of how students' argumentation relates to their scientific knowledge. J Res Sci Teach 45(1):101-131

Wade RC (1994) Teacher education students' views on class discussion: implications for fostering critical reflection. Teach Teach Educ 10(2):231-243

Walshaw M, Anthony G (2008) The teacher's role in classroom discourse: a review of recent research into mathematics classrooms. Rev Educ Res 78(3):516-551

Weaver RR, Qi J (2005) Classroom organization and participation: college students' perceptions. J High Educ 76(5):570-601

Webb NM, Franke ML, Wong J, Fernandez CH, Shin N, Turrou AC (2014) Engaging with others' mathematical ideas: interrelationships among student participation, teachers' instructional practices, and learning. Int J Educ Res 63:79-93

Weiß RH, Weiß B (2006) CFT 20-R, Grundintelligenztest Skala 2, Revision [Test for general fluid ability]. Hogrefe, Göttingen Wells G, Arauz RM (2006) Dialogue in the classroom. J Learn Sci 15(3):379-428 
Wuttke E (2005) Unterrichtskommunikation und Wissenserwerb: Zum Einfluss von Kommunikation auf den Prozess der Wissensgenerierung. [Instructional communication and knowledge acquisition. The influence of communication on the process of knowledge acquisition.] Peter Lang, Frankfurt am Main

Wuttke E (2012) Silence is silver, talk is gold? Analysis of classroom talk in a learner-centred setting. In: Hjörne E, van der Aalsvoort G, de Abreu G (eds) Learning, social interaction and diversity-exploring identities in school practices. Sense Publishers, Rotterdam, pp 103-117

Ziegler A, Ziegler A, Stoeger H (2012) Shortcomings of the IQ-based construct of underachievement. Roeper Rev $34(2): 123-132$

Submit your manuscript to a SpringerOpen ${ }^{\odot}$ journal and benefit from:

- Convenient online submission

- Rigorous peer review

- Immediate publication on acceptance

- Open access: articles freely available online

- High visibility within the field

- Retaining the copyright to your article

Submit your next manuscript at $>$ springeropen.com 